\title{
Laboreal
}

Volume $15 \mathrm{~N}^{\circ} 1 \mid 2019$

Trabalho e cooperação

\section{Primeiro de Maio - trajetória, dimensões e sentidos}

Primero de Mayo - trayectoria, dimensiones y sentidos

Premier Mai - trajectoire, dimensions et sens

First of May - trajectory, dimensions and senses

\section{Marco Aurélio Santana e Alexandre Barbosa Fraga}

\section{(2) OpenEdition}

\section{Journals}

\section{Edição electrónica}

URL: http://journals.openedition.org/laboreal/1597

DOI: $10.4000 /$ laboreal. 1597

ISSN: 1646-5237

\section{Editora}

Universidade do Porto

\section{Refêrencia eletrónica}

Marco Aurélio Santana e Alexandre Barbosa Fraga, «Primeiro de Maio - trajetória, dimensões e sentidos », Laboreal [Online], Volume $15 \mathrm{~N}^{0} 1$ | 2019, posto online no dia 01 julho 2019, consultado o 14 setembro 2020. URL : http://journals.openedition.org/laboreal/1597

Este documento foi criado de forma automática no dia 14 setembro 2020.

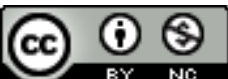

Laboreal está licenciado com uma Licença Creative Commons - Atribuição-NãoComercial 4.0 Internacional. 


\title{
Primeiro de Maio - trajetória, dimensões e sentidos
}

\author{
Primero de Mayo - trayectoria, dimensiones y sentidos \\ Premier Mai - trajectoire, dimensions et sens \\ First of May - trajectory, dimensions and senses
}

Marco Aurélio Santana e Alexandre Barbosa Fraga

\section{NOTA DO EDITOR}

Manuscrito recebido em: dezembro/2018

Aceite após peritagem: fevereiro/2019

1 As comemorações do Primeiro de Maio já têm duradoura e rica trajetória na história do trabalho e dos/as trabalhadores/as. Ao longo de seus cerca de 130 anos, elas assumiram diversas formas, sentidos e conteúdos, internacionalizando-se de maneira que impressiona. Contudo, isso não se deu de forma lisa e linear, sem sobressaltos. Toda a efeméride, por ser uma invenção das tradições (Hobsbawm \& Ranger, 2008), mostra-se resultado de investimentos materiais e simbólicos de indivíduos e grupos com interesses próprios e, por vezes, conflitantes. Nesse sentido, a transformação de um acontecimento em algo a ser lembrado envolve a construção consciente de um conjunto de ideias e de ações não apenas nos primeiros anos em que uma data passa a ser considerada importante, mas durante toda a trajetória de sua celebração. Ao longo desse percurso histórico, quando existem orientações ideológicas e interesses distintos rivalizando em torno de um mesmo evento, frequentemente ocorrem, em menores ou maiores proporções, batalhas da memória (Pollak, 1989, p. 4), nas quais há disputas pelas representações de uma efeméride, pelos sentidos atribuídos a ela e, como consequência, pelas formas de comemorá-la.

2 Esse permanente confronto em torno dos significados atribuídos a uma data que se quer rememorar está presente fortemente em relação ao Primeiro de Maio. A análise 
dos quase cento e trinta anos em que o dia do trabalhador é celebrado no mundo permite constatar a existência de concepções divergentes defendidas tanto por grupos endógenos à classe trabalhadora (em suas diferentes correntes ideológicas, como anarquistas, socialistas, comunistas e conservadores) quanto exógenos a ela (empresariado, grande imprensa, Estado e Igreja), ainda que a configuração desses atores sociais e as representações formuladas por eles variem de acordo com o país e a época. Entre esses distintos sentidos sobre o $1^{0}$ de Maio produzidos em contextos diversos, é possível destacar alguns mais salientes: luto e lembrança daqueles que morreram na defesa da causa operária; protesto, luta e consciência de classe; dia de festa, descanso e feriado nacional; e comemoração da cooperação entre empregados e empregadores. Portanto, enquanto os dois primeiros sentidos compreendem o $1^{\circ}$ de Maio como dia do trabalhador e apresentam uma visão mais combativa, de luto e luta do trabalho contra o capital; os dois últimos enxergam a data como dia do trabalho e indicam uma visão mais harmônica e confraternizadora, de integração do trabalho com o capital.

3 Como nos lembra Danielle Tartakowsky (2005), os $1^{\circ}$ de Maio se sucedem na história, mas não se parecem. Se pudéssemos tomar a experiência francesa como elucidativa de um dos percursos possíveis seguidos na trajetória do Primeiro de Maio, teríamos que ele se conecta, ainda que criticamente, com um conjunto das chamadas festas do trabalho que remontam desde o período da Revolução Francesa, no século XVIII. Uma sucessão de datas foi sendo indicada como comemorativa do trabalho, o que em breve seria questionado e disputado para ser mais uma data dos/as trabalhadores/as do que do trabalho.

4 Já mais próxima das tradições recentes, segundo Rosa Luxemburgo (1894), uma das origens do Primeiro de Maio poderia ser encontrada no movimento realizado por trabalhadores/as da Austrália. Em 1856, trabalhadores/as daquele país decidiram paralisar, em 21 de abril, suas atividades por um dia, organizando reuniões e diversão, em sua luta pela jornada de oito horas de trabalho. A proposta serviria apenas para aquele ano. Contudo, dado o sucesso da ação nos meios operários, ela acabou sendo replicada em anos seguintes. Segundo Luxemburgo, a ideia de uma festa proletária nesses moldes se espalha para outros países ao redor do mundo.

O surgimento do Primeiro de Maio, conforme celebrado até os nossos dias, tem suas origens históricas ligadas a movimentos grevistas ocorridos nos Estados Unidos no século XIX. Após décadas reivindicando a redução da jornada de trabalho para oito horas diárias, em 1886 os sindicatos operários convocaram uma greve geral para o $1^{\text {o de }}$ Maio, data considerada nacionalmente de renovação dos contratos de trabalho e de aluguéis (Moving Day). A greve paralisou cerca de duzentos mil trabalhadores/as. A palavra de ordem era "redução da jornada, sem redução do salário", a partir da concepção de que o dia deveria estar dividido em oito horas de trabalho, oito horas de descanso e oito horas de lazer e estudo. No dia 3 daquele mês, milhares de trabalhadores, ainda em greve, reuniram-se em frente à fábrica McCornick, em Chicago, cidade mais industrializada dos EUA à época. Nessa ocasião, a polícia disparou contra um grupo de operários, deixando um saldo de mortos, feridos e presos (Del Roio, 1986; Avrich, 1986).

6 No dia seguinte, as lideranças dos protestos, sobretudo anarquistas, organizaram um comício na Praça Haymarket contra a repressão sofrida. À noite, quando a concentração já estava se dispersando, policiais atacaram com violência o movimento. Nesse 
momento, uma bomba explodiu entre os guardas, ocasionando a morte de alguns deles. Reforços chegaram e começaram uma brutal repressão, atirando em todas as direções, matando dezenas de trabalhadores, ferindo e prendendo outros milhares. Sedes sindicais foram incendiadas. $O$ episódio ficou conhecido como massacre de Chicago ou massacre de Haymarket. Como consequência direta desses acontecimentos, em junho do mesmo ano, líderes do movimento operário foram presos, julgados e, ainda que não houvesse provas do envolvimento deles nem se conhecesse a autoria da explosão, condenados à morte por enforcamento (Del Roio, 1986; Avrich, 1986).

7 Como o massacre e os mártires de Chicago tornaram-se símbolos mundiais das injustiças do Estado capitalista contra a classe operária, influenciaram a $2^{\mathrm{a}}$ Internacional, organização proletária que buscou superar as fronteiras nacionais, reunindo partidos operários de vários países, sobretudo, europeus. No seu primeiro Congresso, iniciado em 14 de julho de 1889 em Paris, adotou-se uma resolução para que o $1^{\circ}$ de Maio fosse celebrado como Dia Internacional do Trabalho e marcasse a luta pela redução legal da jornada laboral para oito horas diárias. A data, aprovada por aclamação, nascia sob o signo do luto pelos trabalhadores mortos em Chicago e da revolta e da luta por melhores condições de trabalho e de vida, tais como maior tempo de lazer e de descanso (Del Roio, 1986; Kocher, 1987). Interessante notar que, da mesma forma que na experiência australiana, ninguém, nesse momento, pensou que esse ato deveria ser repetido nos anos seguintes. Mas, dado o sucesso em sua efetivação, a data entraria de vez no calendário político e social da classe trabalhadora ao redor do mundo.

8 O ano de 1890 marcou, portanto, o início dessa efeméride em nível mundial, ainda que, em alguns países, a data escolhida para comemorar o dia do trabalhador fosse outra que não o $1^{\circ}$ de maio. Nos Estados Unidos, por exemplo, os seguidores da Segunda Internacional realizaram seus atos à parte, já que a maioria dos sindicatos até hoje dá preferência ao Labor Day, na primeira segunda-feira de setembro. Segundo Hobsbawm (1998), houve um êxito extraordinário das manifestações do Primeiro de Maio de 1890 na Europa, reunindo-se as massas operárias para vivenciarem um sentimento de poder, reconhecimento e esperança, ainda que existissem entre os partidos e movimentos locais discussões e divisões ideológicas sobre as formas legítimas desse tipo de manifestação. A questão fundamental em pauta era se os operários deveriam fazer greve nesse dia. Na Inglaterra, entendeu-se que não e optou-se por uma manifestação no primeiro domingo de maio (dia 4), em vez de no primeiro dia do mês.

9 Ainda que na Inglaterra tenha havido cautela, o Primeiro de Maio foi transformado em vários países, já na sua experiência inicial, em algo mais do que uma ocasião comemorativa, justamente pelo ato de suspender simbolicamente o trabalho, pois abster-se de trabalhar em um dia útil era uma afirmação do poder da classe operária. Foi o que ocorreu, por exemplo, na Áustria. o Congresso da Segunda Internacional em Bruxelas, em 1891, aprovou a manutenção da manifestação no dia primeiro de maio e a suspensão do trabalho onde fosse possível, defendendo também comemorar a data, ou seja, reconhecendo-a não apenas como uma atividade política, mas como uma festa, ideia à qual os anarquistas se opuseram completamente. Para eles, era dia de luto pelos mártires e de luta, e não de comemoração (Hobsbawm, 1998).

10 Já na França, o Primeiro de Maio de 1890 também se tornou, segundo Michelle Perrot (1988), objeto de disputas e de tensões entre seu entendimento como dia de festa e como dia de reivindicação. Essa dupla concepção deu origem a estratégias diferentes, 
das quais fizeram parte grandes desfiles em praças públicas, de forma a reclamar em uma imensa e única voz o direito ao bem-estar e à redução das horas de trabalho, impressionando a opinião pública com tal espetáculo. E das quais fizeram parte também ondas de greves inesperadas, com ações diretas e violentas contra as fábricas. Além desses sentidos de manifestação política e de greve, houve ainda grupos defendendo um feriado pacífico, no qual se pudesse passear com a família, persuadindo os patrões a fecharem os locais de trabalho e converterem o Primeiro de Maio em um dia de dispensa, e não de greve.

11 No caso brasileiro, as manifestações de $1^{\circ}$ de Maio tiveram início na Primeira República (1889-1930). Em 1890 e nos anos seguintes, elas foram marcadas por sessões solenes, passeatas, fogos de artifício, visitas a túmulos de líderes e de operários, atividades de lazer e desfiles das categorias profissionais acompanhados de bandas de música. 0 sentido atribuído à data era o de luto pelos companheiros mortos e de comemoração, congregando caráter festivo e de manifestação política. Com o processo de crescimento da classe operária e o aumento da influência anarquista no movimento, o dia foi passando a ser visto menos como de festa, aumentando o seu entendimento como de recordação aos mártires de Chicago, de greve e de luta. Quanto mais o $1^{\circ}$ de Maio ultrapassava o sentido festivo e tomava as ruas na forma de protestos e atos violentos, mais a grande imprensa mudava a forma de tratá-lo, observando-o com preocupação (Del Roio, 1986; Kocher, 1987).

Sobretudo no decorrer do século XX, a celebração da data como de luta tornou-se predominante, conforme orientação do $1^{\circ}$ Congresso Operário Brasileiro, realizado em 1906. Nele, incitou-se o operariado a celebrar o $1^{\circ}$ de Maio não como festa, mas como protesto e reivindicação de direitos, inclusive a redução da jornada de trabalho sem diminuição dos salários. Passaram a ocorrer greves e paralisações e uma celebração mais combativa. Com isso, acirrou-se a disputa pelo significado da data, não apenas entre os trabalhadores, mas por outros atores sociais. A Igreja Católica, a imprensa e o Estado buscavam retirar os contornos políticos da celebração, enfatizados nos discursos anarquista e comunista, e incentivar seu caráter festivo e de integração capitaltrabalho. Essas tentativas culminaram na transformação do Primeiro de Maio em feriado nacional pelo presidente Artur Bernardes, em 1924. Com essa estratégia, a paralisação nesse dia deixou de ser iniciativa dos trabalhadores, como demonstração de força, e passou a ser uma concessão do Estado em homenagem à festa do trabalho (Del Roio, 1986; Kocher, 1987; Arêas, 1997/1998).

13 O controle da data pelo Estado e a sua apropriação para atender a interesses governamentais tiveram como ápice a Era Vargas, sobretudo durante o Estado Novo (1937-1945). Nos constantes discursos de Primeiro de Maio proferidos por Getúlio Vargas, em diferentes locais, e a partir de 1939 no estádio de São Januário, o sentido de um dia de luta do trabalho contra o capital foi substituído por um dia de festividade oficial conduzida pelo governo, de alegrias e de confraternização das classes sociais com o Estado, celebrando a colaboração entre trabalho e capital e a promulgação de leis trabalhistas (Lima, 1990; Gomes, 2005). Nas comemorações, os trabalhadores ocupavam um lugar de destaque, mas o protagonismo foi deslocado para o Estado, na figura de Vargas, e para o desenvolvimento econômico, conquistado, nessa concepção, pela cooperação entre empregados e empregadores.

Deve-se indicar também que, mesmo no período da Ditadura militar (1964-1985), a classe trabalhadora brasileira buscou, nessa data, apresentar suas reivindicações e sua 
posição sobre o estado de coisas em que vivia. O ano de 1968 é um marco nesse sentido. Organizado por uma coalização de forças de esquerda e setores conservadores, o Primeiro de Maio desse ano, em São Paulo, foi uma das componentes do 1968 operário no Brasil. Contrariando os setores de esquerda, alguns já conectados com grupos revolucionários armados, os setores conservadores decidiram convidar autoridades políticas, inclusive o governador do Estado. Durante a fala dessas autoridades, as forças de esquerda resolveram tomar de assalto o ato público, entoando palavras de ordem radicais, atirando pedras e, finalmente, ateando fogo ao palanque.

Todos esses sentidos atribuídos ao Primeiro de Maio ao longo do tempo apresentam-se não na forma de uma linearidade, mas como uma espiral de concepções que fazem parte tanto da memória operária quanto de um imaginário social mais amplo e que, portanto, podem ser defendidas simultaneamente por grupos diversos atualmente: luto pelos trabalhadores que sucumbiram; luta por melhores condições de trabalho ou pela emancipação; festa, feriado e comemoração; e conciliação de classes. A nomeação como dia do trabalhador ou dia do trabalho revela, então, uma disputa político-ideológica. Se pende para a segunda forma, demonstra um afastamento do significado político que lhe deu origem. Se, ao contrário, pende de maneira crítica para a primeira forma, possibilita que os trabalhadores reflitam sobre o seu lugar e a respeito de suas experiências (Thompson, 1987), em uma conjugação de passado, presente e futuro, a qual evoca mais a luta do que a comemoração.

16 Levando em consideração essa espiral de concepções, duas indicações finais importantes precisam ser feitas em termos dessas disputas, em tempos mais recentes e considerando os atores sociais e políticos presentes. Apesar de situações particulares, podem lançar luz sobre os mesmos processos que têm ocorrido em outras experiências. De um lado, a tentativa de setores e partidos conservadores de ocuparem o seu espaço nessas celebrações, buscando lhe imprimir seu próprio viés. O caso da França (Tartakowsky, 2013) é bastante interessante. Já desde 1988 o Front National dos Le Pen vem fazendo aproximações continuadas nesse sentido. Em 2012, os partidários de Nicolas Sarkozy buscaram empreender um Primeiro de Maio do "verdadeiro trabalho". Em 2013, a direita francesa buscou sincretizar sua luta contra o casamento para todos com essa data.

Por outro lado, e, aí, com viés progressista, é sentida a tentativa de setores da classe trabalhadora, que têm experimentado as agruras das novas formas de produção e acumulação capitalista em sua ponta da exclusão e precarização, e que nem sempre tiveram atenção devida das engrenagens sindicais e, muitas vezes, organizaram-se para além e até contra elas, buscarem também seus espaços no Primeiro de Maio. Em 2018, por exemplo, os Precários Inflexíveis sinalizavam que naquele $1^{\circ}$ de maio em Portugal “também a voz de quem está desempregado se fará sentir... No primeiro de Maio a voz dos precários encontra-se na rua!".

Pode-se dizer, portanto, que, a partir de certo ponto de vista, o Primeiro de Maio, apesar de todas as dificuldades enfrentadas pelas forças sociais do trabalho nessa quadra do capitalismo, tem seu espaço garantido em termos futuros. Como assinala Rosa Luxemburgo (1894), o Primeiro de Maio reivindicava a instauração das 8 horas, mas, mesmo depois de atingido esse objetivo, a data não foi abandonada. Segundo ela, enquanto durar a luta entre os trabalhadores e a burguesia, e enquanto as reivindicações não forem aceitas, a data permanecerá. E, mesmo quando dias melhores vierem, e a classe operária obtiver sua vitória final, "ainda assim a humanidade 
festejará o $1^{\circ}$ de Maio, em honra das lutas encarniçadas travadas e dos numerosos sofrimentos sofridos no passado" (Luxemburg, 1894, p. 3, tradução livre).

\section{BIBLIOGRAFIA}

Arêas, L. (1997/1998). As comemorações do primeiro de maio no Rio de Janeiro (1890-1930).

História Social, 1, 4/5, 9-28.

Avrich, P. (1986). The Haymarket tragedy. New Jersey: Princeton University Press.

Del Roio, J. (1986). 1º de maio. Cem anos de luta. 1886-1986. São Paulo: Global Editora.

Gomes, A. (2005). A invenção do trabalhismo. Rio de Janeiro: Editora FGV.

Hobsbawm, E. (1998). O nascimento de um feriado: o primeiro de maio. In E. Hobsbawm (Ed.).

Pessoas extraordinárias: resistência, rebelião e jazz (pp. 169-190). São Paulo: Paz e Terra.

Hobsbawm, E., \& Ranger, T. (Orgs.) (2008). A invenção das tradições. Rio de Janeiro: Paz e Terra.

Kocher, B. (1987). Luto-luta: o primeiro de maio no Rio de Janeiro (1890-1940). Dissertação de Mestrado. Instituto de História da Universidade Federal Fluminense, Niterói.

Lima, M. (1990). A construção discursiva do povo brasileiro: os discursos de 1ํ de maio de Getúlio Vargas. Campinas: Editora da UNICAMP.

Luxemburg, R. (1894). Quelles sont les origines du 1er mai? Sprawa Robotnicza, 8 février, 2-3.

Perrot, M. (1988). o primeiro Primeiro de Maio na França (1890): nascimento de um rito operário. In M. Perrot (Ed.). Os excluídos da história: operários, mulheres e prisioneiros (pp. 127-164). Rio de Janeiro: Paz e Terra.

Pollak, M. (1989). Memória, esquecimento, silêncio. Estudos Históricos, 2, 3, 3-15.

Tartakowsky, D. (2005). La part du rêve. Histoire du 1er Mai en France. Paris: Hachette Littératures.

Tartakowsky, D. (2013). Les Premiers mai se suivent... Le Huffington Post, 1er mai.

Thompson, E. (1987). A Formação da Classe Operária Inglesa. Rio de Janeiro: Paz e Terra.

\section{AUTORES}

\section{MARCO AURÉLIO SANTANA}

Departamento de Sociologia e Programa de Pós-Graduação em Sociologia e Antropologia; Instituto de Filosofia e Ciências Sociais (IFCS); Universidade Federal do Rio de Janeiro (UFRJ). Largo de São Francisco de Paula, 1, sala 416 - Centro. Rio de Janeiro, Brasil, 20051-070 marcosilvasantana@gmail.com.br

\section{ALEXANDRE BARBOSA FRAGA}

Programa de Pós-Graduação em Sociologia e Antropologia da UFRJ alexbfraga@yahoo.com.br 